\title{
Patient Life Experience and Activity of Daily Living before and after Total Knee Arthroplasty
}

\author{
Pi-Chu Lin1*, Kimie Fujita², Su-Yu Chang3,4, Yo-Yi Liu ${ }^{5}$ \\ ${ }^{1}$ Master Program in Long-Term Care and School of Nursing, College of Nursing, Taipei Medical University, Taiwan \\ ${ }^{2}$ Department of Health Sciences, Faculty of Medical Sciences, Kyushu University, Fukuoka City, Japan \\ ${ }^{3}$ School of Nursing, Taipei Medical University, Taiwan \\ ${ }^{4}$ Department of Nursing, Taipei Veterans General Hospital, Taiwan \\ ${ }^{5}$ Department of Nursing, Taipei Medical University Hospital, Taiwan \\ Email: ${ }^{*}$ pclin02@gmail.com, fujitak@hs.med.kyushu-u.ac.jp, sychang6@vghtpe.gov.tw, Taiwan.Rado@h.tmu.edu.tw
}

How to cite this paper: Lin, P.-C., Fujita, K., Chang, S.-Y. and Liu, Y.-Y. (2016) Patient Life Experience and Activity of Daily Living before and after Total Knee Arthroplasty. Open Journal of Nursing, 6, 658671.

http://dx.doi.org/10.4236/ojn.2016.69069

Received: August 5, 2016

Accepted: September 2, 2016

Published: September 5, 2016

Copyright $\odot 2016$ by authors and Scientific Research Publishing Inc. This work is licensed under the Creative Commons Attribution International License (CC BY 4.0).

http://creativecommons.org/licenses/by/4.0/ (c) () Open Access

\begin{abstract}
Background: As the population ageing, more patients suffer from joint disease. Joint replacement surgery performed in Taiwan is about 10,000 to 20,000 cases yearly. Aims: The purpose of this study is to realize Total Knee Arthroplasty (TKA) patients' views about life experiences and difficulty in daily life before and after the surgery. Methods: In this study, in-depth interview with interview guideline was used to analyze patients' experience by using a qualitative research method, and questionnaires were used to collect quantity data. Results: 1) A total of 20 participants were recruited. Average age was $75.15(\mathrm{SD}=6.468)$. Eighteen of the participants were female and the other two were male. The majority of participants indicated that their home facilities were convenient or very convenient. 2) Motivations of the participants to undergo TKA were joint pain, limited joint range of motion, and weakness in legs. Participants' expectations after surgery were no more pain and ease in walking, and able to manage daily life. 3) Depending on the time after surgery, joint pain and walking ability had improved to some extent. The joint range of motion increased, but kneeling remained difficult, and the participants' mood and exercise capacity were improved. Conclusions: The finding can be as a reference for clinical practitioner to provide preoperative education for total knee arthroplasty patients.
\end{abstract}

\section{Keywords}

Total Knee Arthroplasty, Quality of Life, Activities of Daily Life, Patient Experience, Qualitative Research 


\section{Introduction}

As the number of older people in Taiwan increases, so does the proportion of individuals with osteoarthritis. Severe osteoarthritis causes pain and disability, posing a heavy burden on patients. Knee replacement is a common orthopaedic procedure that can greatly improve quality of life and provide pain relief [1]. Past studies have tracked Total Knee Arthroplasty (TKA) surgical outcomes; and most of these have been quantitative studies following up on patient joint function, pain, and quality of life with questionnaires [2] [3]. Questionnaires that have been used include the 36-Item Short Form Health Survey (SF-36) [4]-[6], Western Ontario and McMaster Universities Arthritis Index (WOMAC) [4] [6] [7], Knee injury and Osteoarthritis Outcome Score [8], Arthritis Impact Measurement Scales 2 [9] [10], and Lysholm Knee Scoring Scale [11]. Only a few qualitative studies examining the experiences of artificial hip and knee replacement patients exist [12] [13]. Fujita et al. interviewed 20 artificial hip patients and found that patients exhibited significant improvement postoperatively in terms of pain and disability, but also faced significant body image stress related to their artificial joint [12]. Gustafsson et al. used a phenomenological hermeneutical approach to study participant experiences of hip and knee replacement intervention across the entire perioperative period. Sixteen participants aged $\geq 65$ years old were recruited, and the study illuminated the meaning of reflections related to hip and knee replacement surgery. Four themes were identified: Choosing the challenge, past memories relating to the current situation, moving from happiness to everyday life, and moving from despair towards reluctant acceptance of unexpected poor health in everyday life. The participants exhibited inner negotiations about whether to undergo surgery and existential anxiety indicating to them that life cannot be taken for granted [13].

Although joint replacement has proven substantially more effective than implanted prosthesis, with up to $80 \%$ of artificial joints lasting over 15 years, TKA prostheses originated in the West, with artificial joint design and development primarily conducted for Westerners and in consideration of Western lifestyles and needs. Artificial joint design is largely conducted by using the Activities of Daily Living (ADLs) of Westerners for determining hip and knee range of motion, geometry, dimensions, and design. Although in the Taiwanese lifestyle, dissimilar to that of the Japanese, kneeling and sitting cross-legged is not common [14], typical families reside in apartment-style residences and therefore must climb stairs to enter into their homes or access indoor elevators. This daily stair climbing poses significant challenges for patients with severe joint disease and for patients who have received artificial joint replacements. Artificial joints are designed to satisfy the needs of Western patients, and whether they are similarly suitable for East Asians is unclear. Because many patients anticipate the ability to completely engage in regular daily activities after receiving a joint replacement, determining whether artificial joints satisfy the needs of East Asians is also critical.

\section{Aims}

Therefore, the purpose of this study was to elucidate TKA patients' views about their 
life experiences and difficulty in daily life before and after the surgery.

\section{Methods}

In this study, in-depth interview with interview guideline was used to analyze patients' experience by using a qualitative research method, and questionnaires were used to collect quantity data.

\subsection{Participants}

Purposive sampling and snow-ball methods were used to recruit patients at orthopaedic ward or OPD. Inclusion criteria: 1) could speak Mandarin or Taiwanese; 2) admitted for TKA or post TKA. Exclusion criteria were difficulties in speaking and understanding the Mandarin Chinese and obvious dementia. Interview patients until data saturated, after 20 interviews, no new categories or subcategories were developed, and then we stopped data collection. Total of 20 TKA patients were interviewed in this study.

\subsection{Data Collection}

All patients were informed about the study purpose and interviewing process verbally by the correspondent author. After giving their written consent, the hospitalized patients were guided to the meeting room of the ward, while for OPD patients who were arranged in an unoccupied room, where interviewing were conducted by the correspondent author who have had 30 years of orthopaedic clinical experience. Interview guide was developed by Prof. Fujita et al. (Table 2) [11]. Interviews were tape-recoded. Each interview took about 30 - $40 \mathrm{~min}$. After each interviews completed, the researcher repeated listening to recordings and interviews were translated into text file. Demographic data and data on diseases and past operative experience were collected from the patient records.

\subsection{Analysis}

Data were analyzed using qualitative content analysis as described by scholars [15]. First, the recorded tapes were repeatedly listened to and all the interview records were read through in order to get an overall sense of the patients' views. Next, the verbatim data were read line-by-line in order to identify statements related to TKA. These statements were marked, and tentative codes were written in the margin for the detection of emerging patterns. Differences and similarities among codes were compared, and codes that were similar in content were subsequently grouped and classified into various categories.

\subsection{Trustworthiness}

In this study, Lincoln and Guba [16] qualitative research raised the trustworthiness was used as the evaluation criteria.

In truth, the majority of respondents through snowball manner, they were introduced by familiar person and they should be pleased to provide experience and estab- 
lish a trust relationship with the researchers, in order to authenticity and reliability of the information provided. To validate the results, responses to questions were further probed several times during the interview, to gain deeper understanding.

In this study, data from in-depth interviews and from many different backgrounds living experience undergoing knee replacement surgery before and after surgery, it is gathered from a wide range of information can increase the future applications. Coding and development of the categories were done by the first author. The third author read all the condensed units of meaning and also questioned the preliminary analysis.

\subsection{Ethical Considerations}

Ethical considerations were observed according to the recommendations of Helsinki declaration, as suggested by Wilkie (1997) [17]. The Research Ethical Committee at the TMU Hospital approved the study (IRB No. 201503030). Before the study all participants were informed the right to stop interview any time. To take account of privacy and human rights, patient real name would not appear in the results and the code instead of the patient's name.

\section{Results}

\subsection{Basic Information and Lifestyle of Participants}

This study interviewed 20 patients who underwent artificial joint replacement. The average age was 75.15 ( $\mathrm{SD}=6.468)$, between 67 - 83 years age. Eighteen of the participants were female and the other two were male. Among them, six were preoperative patients (30\%), eight patients were 2 - 3 months post surgery (40\%), and six patients were 1 - 3 years post surgery (30\%). More demographic data can be found in Table 1 .

The participants were asked whether they were inconvenienced in their daily lives by their inability to squat. In response, all the participants indicated that they used sitting toilets at home, and because most of their beds and dining tables were of normal height, they were able to eat while sitting. A more common inconvenience was the need to climb stairs to return home or to climb indoor stairs inside homes. However, when the participants were asked if their living circumstances were convenient, the vast majority of them indicated that their home facilities were convenient or very convenient; only three indicated that their living circumstances were inconvenient. The respective lifestyles of the research subjects are shown in Table 1.

\subsection{Motivations of the Participants to Undergo TKA}

Three major themes can be drawn from the experiences of the participants (Table 2).

\subsubsection{Knee Joint Pain}

Many participants complained that pain while walking and the inability to walk long distances. C18 said: "The pain is so serious I can't even walk. Walking is so painful, I can't walk at alP". C3 said: "The director [the doctor] said that the bone is all worn down. It was really painful before I had the surgery". Other participant said: "I just 
Table 1. Basic information and lifestyle of the participants.

\begin{tabular}{|c|c|c|c|c|c|c|c|c|}
\hline \multirow[b]{2}{*}{ Case No. } & \multicolumn{3}{|c|}{ Basic information } & \multicolumn{5}{|c|}{ Home environment } \\
\hline & Age & Sex & Pre/post-op (mo.) & $\begin{array}{l}\text { Stairclimbing/ } \\
\text { indoor obstacles }\end{array}$ & Toilet & Dining table & Bed height & $\begin{array}{l}\text { Living convenience } \\
\text { at home }\end{array}$ \\
\hline 1 & 83 & 2 & 12 & No/Yes & Sitting & Normal height & Standard & Very convenient \\
\hline 2 & 79 & 2 & 2 & No/Yes & Sitting & Normal height & Standard & Convenient \\
\hline 3 & 87 & 2 & 12 & $\mathrm{Yes}(3 \mathrm{~F}) / \mathrm{No}$ & Sitting & Normal height & Standard & Very convenient \\
\hline 4 & 76 & 2 & 2 & Yes $(2 \mathrm{~F}) / \mathrm{Yes}$ & Sitting & Normal height & Standard & Convenient \\
\hline 5 & 75 & 2 & Pre-op, & Yes $(2 \mathrm{~F}) / \mathrm{Yes}$ & Sitting & Normal height & Standard & Slightly inconvenient \\
\hline 6 & 76 & 1 & Pre-op, & No/No & Sitting & Normal height & Standard & Very convenient \\
\hline 7 & 75 & 2 & Pre-op, & Yes $(2 \mathrm{~F}) / \mathrm{Yes}$ & Sitting & Normal height & Standard & Convenient \\
\hline 8 & 80 & 2 & Pre-op, & No/No & Sitting & Normal height & Standard & Convenient \\
\hline 9 & 73 & 2 & Pre-op, & Yes $(2 \mathrm{~F}) / \mathrm{Yes}$ & Sitting & Normal height & Standard & \\
\hline 10 & 69 & 2 & 2 & $\mathrm{No} / \mathrm{No}$ & Sitting & Normal height & Standard & Very convenient \\
\hline 11 & 66 & 2 & 2 & Yes $(4 \mathrm{~F}) / \mathrm{No}$ & Sitting & Normal height & Floor Level & Very convenient \\
\hline 12 & 67 & 2 & 2 & $\mathrm{Yes}(2 \mathrm{~F}) / \mathrm{No}$ & Sitting & Normal height & Standard & Very convenient \\
\hline 13 & 84 & 2 & 3 & $\mathrm{Yes}(4 \mathrm{~F}) / \mathrm{No}$ & Sitting & Low stool & Standard & Convenient \\
\hline 14 & 70 & 2 & 12 & Yes $(4 \mathrm{~F}) /$ Yes & Sitting & Normal height & Standard & Slightly inconvenient \\
\hline 15 & 70 & 1 & Pre-op, & $\mathrm{Yes}(3 \mathrm{~F}) / \mathrm{No}$ & Sitting & Normal height & Standard & Convenient \\
\hline 16 & 73 & 2 & 2 & $\mathrm{Yes}(3 \mathrm{~F}) / \mathrm{No}$ & Sitting & Normal height & Standard & Convenient \\
\hline 17 & 76 & 2 & 24 & $\mathrm{Yes}(2 \mathrm{~F}) / \mathrm{No}$ & Sitting & Low stool & Standard & Convenient \\
\hline 18 & 78 & 2 & 36 & Yes $(4 \mathrm{~F}) / \mathrm{Yes}$ & Sitting & Low stool & Standard & Convenient \\
\hline 19 & 76 & 2 & 2 & No/Yes & Sitting & Normal height & Standard & Slightly inconvenient \\
\hline 20 & 70 & 2 & 22 & $\mathrm{Yes}(2 \mathrm{~F}) / \mathrm{No}$ & Sitting & Normal height & Standard & Very convenient \\
\hline
\end{tabular}

Table 2. Interview guide and theme of participant experiences.

\begin{tabular}{|c|c|}
\hline Interview guide & Theme of participant experiences \\
\hline \multirow{4}{*}{$\begin{array}{l}\text { 1) Motivation of participants to } \\
\text { undergo TKA }\end{array}$} & Primary reasons participants pursued surgical treatment: \\
\hline & 1) Knee joint pain: Walking is painful and inability to walk long distances \\
\hline & 2) Limited joint range of motion: Difficulty climbing stairs and inability to bend down or squat \\
\hline & 3) Weakness in legs: Limpness and difficulty walking \\
\hline \multirow{2}{*}{$\begin{array}{l}\text { 2) Expectations of participants } \\
\text { about TKA }\end{array}$} & 1) No more pain and ease in walking \\
\hline & 2) Able to manage daily life \\
\hline \multirow{7}{*}{$\begin{array}{l}\text { 3) Life changes from preoperative } \\
\text { to postoperative periods }\end{array}$} & 1) Initial postoperative outdoor walking capabilities differ depending on the individual \\
\hline & 2) Pain improved: Participants are able to walk farther and do what they want to do postoperatively. \\
\hline & 3) Joint range of motion improves postoperatively, but squatting remains difficult \\
\hline & $\begin{array}{l}\text { 4) Improved mood: Normalisation of daily life post operation and ease in going outdoors, leading to } \\
\text { improved participant mood }\end{array}$ \\
\hline & 5) Increase the amount of exercise: Participants forced to reduce exercise volume prior to surgery, \\
\hline & but could gradually increase exercise after surgery \\
\hline & $\begin{array}{l}\text { 6) ADL difficulty: Participants able to conduct ADL preoperatively, but ADL remained difficult } \\
\text { within } 3 \text { months after surgery }\end{array}$ \\
\hline
\end{tabular}


can't walk for a long time. It hurts, so I can't walk far" (C2). C1 said: "Walking is very difficult, so I don't walk far and don't want to leave the house." A family member of C13 said: "Before Mom had her surgery, we would hear her screaming, 'Ah! $A h$ ! Ah!"” C6 said: "When I want to get out, I meet difficulties getting on and off vehicles, so I try to avoid it as much as possible".

\subsubsection{Limited Joint Range of Motion}

Participants complained that difficulties climbing stairs and standing up after sitting for long periods of time and the inability to bend down or squat. C18: "I couldn't stand or climb stairs, so I had to get surgery". "Standing up after sitting down hurts, so I can't stand up" (C13). C14 said: "Climbing up and down stairs is more difficult and takes more energy, so I have to do it slowly while holding onto the handrails". "All the cartilage inside has degenerated, so it hurts, and I can't bend down" (C19). Other participants (C16) said: " $P m$ afraid of squatting now, and I can't even kneel either". "My joints are tight, and so I can't stand up after sitting for a long time" (C17).

\subsubsection{Weakness in Legs}

Because of weakness in legs, participants complained difficulty walking and limping. C6 said: "I don't have strength after walking for longer distances-my legs feel limp, and I feel very tired after buying groceries at the market. I decided to get surgery because walking is inconvenient". C2 similarly said: "[There is] no strength in my legs. [I] walk unsteadily. I drag my feet [and am] very tired when I walk. [ $]$ walk slower. I can't stand for a long time, I can't stand it. All of my movements are more difficult". C4 said: "It doesn't hurt, I just don't have any strength in my legs'.

\subsection{Expectations of the Participants about TKA}

The expectations identified from the interviews are as follows.

\subsubsection{No More Pain and Ease in Walking}

The participants expected that they would be able to walk after the surgery. "To be able to walk, to be able to run! Just as long as I don't hurt anymore" (C19). "I just hope that it won't hurt anymore after I have the surgery and I will be able to walk well” (C3). "I hope that it won't hurt anymore after the surgery and I will be able to walk normally" (C15).

\subsubsection{Able to Manage Daily Life}

The participants anticipate self-care independently after the operation is completed. "The main thing is so that it stops hurting, and then being able to manage my own life" (C1). "I hope that I will be able to conduct normal activities and go through daily routines normally" (C20). "My family members all encourage me to go through with the operation. They tell me that after I have the operation, we can travel throughout Taiwan on vacation every year and walk wherever we want to walk' (C5).

\subsection{Life Changes from the Preoperative to Postoperative Period}

The changes in the lives of the participants from the preoperative stage to $2-3$ months 
or 1 - 3 years post operation summarised from the interviews are as follows.

\subsubsection{Initial Outdoor Walking Capabilities Differed Depending on the Individual}

For example, C2 (2 months post operation) said: "I haven't left home since the operation. I can't go out to buy things, and it's harder to walk-it's very tiring to walk'. However, some of the participants were able to engage in outdoor activities soon after the operation; C13 (3 months post operation) said: "I walked down the stairs and out [of the house] three days after the operation. I go to the park every day and walk outside every day. I bring an umbrella with a small, black anti-slip tip when I go out. If it hurts a little, then I walk slowly". C4 (2 months post operation) said: "Today, I took the train from Hsinchu, then the MRT, and then the bus up here [to Taipei for a check-up]. My husband came with me, and I ve been able to get on and off vehicles just fine".

\subsubsection{Pain Improved}

Participants are able to walk farther and do what they want to do. Because walking was painful prior to the operation, the participants were unable to walk long distances and therefore did not want to go outside. When the participants had to go out, they had to be cautious; some participants only rode motorcycles when travelling outside. One year after the operation, most of the participants indicated that they were satisfied with walking, going outdoors, and their daily lives. Although a few participants continued to experience a mild degree of pain, it improved after the operation.

For example, C14 (1 year post operation) said: "I couldn't really walk before the operation, but now I can walk much better. I started walking downstairs about 1 or 2 months after the operation". Similarly, C1 (1 year post operation) said: "It stopped hurting after the operation-now I can walk far without anyone accompanying me". C20 (22 months post operation) said: "I can walk to places far away and have no problems leaving the house. My daily life is normal'.

Some participants indicated that they still felt joint pain after the operation, such as C14 (1 year post operation), who said: "It still hurts when I get up [from the toilet] after the operation. This tendon back here is very tight and painfuP'. C3 (1 year post operation) said: "I thought that it would stop hurting after a few months. I didn't think that it would still be swollen and painful even after a year. The recovery process has been slower than I thought, but it is improving. To be honest, I regretted my decision when I first returned home because of the pain, but the pain before the operation is different from the pain after the operation. It was really hard to stand before the operation, but it really improved after the operation".

\subsubsection{Joint Range of Motion Improved but Squatting Remained Difficult}

Climbing stairs was difficult because of limited joint range of motion before the operation. Furthermore, participants were unable to squat and had a difficulty getting up after sitting for a long time. These conditions improved post operation, but the participants were still unable to squat.

For instance, participants indicated that: "It was really hard climbing stairs before the 
operation. It was really slow, and I had to hold on to the handraip" (C14). "I crawled up stairs while holding onto the handrail, grabbing onto it until my hands hurt" (C5). "Walking down stairs was painful, and sometimes my legs would feel weak. It wasn't easy" (C7). "I couldn't squat before the operation and it hurt when I stood up after sitting down for a long time, so I tried to sit in a low chairs as little as possible. Standing up from the sofa was difficult, so I stood up slowly instead of all at once. Otherwise, I just got up while holding onto the side, like this" (C6).

Postoperative participants said: "Although my knee movement has improved, it is still not ideal-I still can't squat" (C20, 22 months post operation). "I still can't do a squatting motion; I couldn't squat before the operation and I still can' 't" (C1, 1 year post operation). "It can't bend! I still can't squat. Maybe it has to do with rehab. My legs are still really tight, and I can't do anything about it" (C18, 3 years post operation).

However, one participant reported no improvement after the operation: "I could still squat before the operation, but not anymore. Before the operation, I would go to church and kneel, but now my priest tells me not to kneel. My friends can do the splits and sit cross-legged, and I can't do either' (C3, 1 year post operation).

\subsubsection{Improved Mood}

Due to the normalisation of daily life post operation and fewer problems going outdoors, the participants experienced more positive moods. For example, C1 said: " $I$ was more or less depressed before the operation because I was different from other people. Now 11 year post op] I walk very naturally and can go out for walks every morning. Morning walks are the best - I can walk far away and go out to see the sights. My mood is better-I mean $1 \mathrm{~m}$ in better spirits. I don't need to put on ointment all day. I have kidney disease, so I can't take painkillers, and now I don't need to, so my kidneys have gotten better". C20 said: "Now [1 year post op] I can go to the market to buy groceries by myself. I go every day now since it doesn' thurt. I can go farther and do what I want, like exercising, shopping, going to the market. My mood is really different now".

\subsubsection{Increased the Amount of Exercise}

Participants were forced to reduce their regular exercise prior to the operation because of knee pain. Although the participants were unable to return to their regular exercise routine in the initial period after the operation, the amount of exercise they could perform began gradually increasing after 1 year.

Regarding the preoperative period, C7 said: "I usually exercised, but I stopped [doing so] about a month before the surgery because my knee started hurting”. C13 said: "When I went out on trips before the operation, I couldn't walk at all. I would ride the car to a set point and just sit there waiting, just to get some fresh air away from home. And then I would get in the car when it was time to get in, and then [later, at destinations] I would get out and take a look, because I couldn't walk". Similarly, C5 said: "I couldn't participate when going to some scenic spots. If they required walking, I would just sit down and wait for everyone to come back".

Two months post operation, mobility had yet to recover, as in the case of C2 (2 
months post operation): "I used to grow vegetables before the operation-it was a form of exercise. Now, after the operation, I can't bend down, so I can't go plant." C3 (1 year post operation) said: "There is a school next door, so I go there every day to exercise. I walk quickly for 30 minutes, then do some exercises".

\subsubsection{ADL Difficulty}

Patients suffering from osteoarthritis of the knee did not affect the execution of ADL preoperatively, but ADL difficulties within 3 months post operation.

Most of the participants were able to care for themselves prior to surgery; they were able to perform housework and prepare meals. For instance, $\mathrm{C} 1$ and 6 said: " $I$ could shower, do housework -I did everything by myself, including preparing three meals a day. Buying ingredients was easy, and I did my laundry and cleaned my house myself. I would alternate between doing chores and resting". C5 said: "I really didn't have any problems taking care of myself before the operation. I would even help bathe my grandchildren, cook, and do laundry by myself. When my grandchildren would come back they would need to eat, but my husband did the mopping". C7 said: "I would do all the housework by myself before the surgery without any problems".

There were difficulties in the execution of ADL within 3 months post operation. C2 (2 months post operation): "When I use the toilet, I need to hold on to a handrail with one of my legs bent like this". C13 (3 months post operation): "I have to hold on to the walls when I walk around at home. I need something to hold, and so I hold on to the handrails when I climb up and down stairs". C2 (3 months post operation) said: "I need to use my arms when standing up from a chair, and I need to hold on to a handrail when standing up from the toilet". Furthermore, C19 (6 months post operation) said: "I currently have some problems in my daily life because of this leg, so $1 \mathrm{~m}$ still afraid of going out". C4 (2 months post operation), who lived in a three-storey building, said: "I've been afraid of going upstairs since the operation. I can't, so I just stay on the first floor".

\section{Discussion}

This study conducted in-depth interviews regarding the subjective life experiences of TKA patients before and after the operation. The main interview topics-experiencing joint pain and difficulty walking before the operation, changes from before and after the operation, and changes in ADL difficulty before and after the operation-are discussed as follows.

\subsection{Experiencing Joint Pain and Difficulty Walking before the Operation}

Most of the participants decided to undergo surgery because of knee joint pain. Walking was painful, preventing them from walking long distances or to their desired locations. Furthermore, participants indicated difficulty climbing up and down stairs; although they were not completely unable to climb stairs, doing so constituted a great challenge for them. The inability to bend down was also a problem, as was the sensation 
of leg weakness and limpness. These factors affected the quality of life and mood of the participants. These results are similar to those of Lin [18], who examined preoperative pain in 93 (83.9\% TKA) artificial hip and knee replacement patients. The patient experiencing the most pain had a total of 3.87 points (on a 0 - 10-point scale), whereas the average pain index for the patients was 1.93 points, indicating that they endured significant joint pain prior to the operation. These results are also consistent with Desmeules et al. [19], who showed that patients waiting for knee replacement have poor function, knee pain, stiffness, and HRQoL.

As such, patient expectations towards receiving artificial knee joint replacement surgery are based on their hopes of reducing joint pain, having healthy legs, and regaining freedom of movement; all patients hope to normalise their lives. As emphasised by Parke [20], postoperative measures for artificial knee replacement surgery should focus on reducing pain and rehabilitation exercises to restore walking ability. These findings are consistent with those of Rudan, Harrison, and Grant [21], indicating that reducing pain and restoring walking ability are the main hopes of patients undergoing artificial hip and knee replacement.

\subsection{Major Changes before and after Surgery}

After surgery, the participants primarily exhibited improvement in terms of pain. This study found that walking ability was typically poorer during the initial $2-3$ months post operation compared with before the surgery. However, the ability to walk longer distances gradually improved over time. Regarding mobility, because most of the participants lived in homes that required stair climbing, some were able to walk down stairs and go outdoors soon after surgery, whereas others rarely left their homes in the 2 - 3 months post operation. As such, when medical personnel provide health education for patients before the operation, they should clearly let patients know that joint surgery does not restore regular function rapidly, thereby preventing the patients from holding incorrect expectations and being disappointed. Interviews with the participants 1 - 3 years post operation revealed significant improvement in walking and mobility ability. When people are able to walk outdoors and do what they like, they naturally have a higher quality of life. Past studies have utilised questionnaires to track patient pain, body function, and quality of life before and after undergoing artificial knee joint replacement surgery, but few have examined the effects of knee joint range of motion on patient lifestyle after surgery. The findings of this study confirm the findings of past quantitative research.

A systematic review by Ethgen et al. of 74 studies on TKA or THA patient quality of life reported that overall, these procedures were found to be quite effective in terms of improvement in health-related quality-of-life dimensions, with the occasional exception of the social dimension [2]. Jones and Pohar reviewed 33 articles and found that after total hip and knee arthroplasty, disease-specific measures reported large and crucial changes, primarily for pain and function over short- and long-term recovery [3].

Regarding the improvement process of post arthroplasty surgery, scholars have 
found that joint pain improved between 6 weeks [10] and 3 months after surgery, whereas walking and mobility required 3 and 6 months, respectively, for recovery [10]. Furthermore, Chen found that patients exhibited significant improvement in all categories (role physical, physical functioning, bodily pain, general health, social functioning, mental health, and role emotional) of the SF-36 quality of life survey 3 months after the surgery, except for "vitality", which did not reach a level of statistical significance. Furthermore, the pain, stiffness, and physical function indices of WOMAC exhibited significant improvement 3 months after hospital discharge compared with preoperative conditions [4]. Hsu tracked patient quality of life for 3 months following surgery and found that patients exhibited significant improvement on both the SF-36 and WOMAC scales [6]. In addition, Chen tracked TKA patients for 6 months to 1 year after surgery and found that they exhibited moderate quality of life after the surgery, with social interaction function scoring the highest and symptomatic function scoring the lowest [9]. Nunze et al. conducted a prospective study with 7 years of follow-up. Significant differences were observed between pre- and post-operative WOMAC pain, stiffness, and function scores, especially for the pain dimension. Overall, $86 \%$ of the patients were satisfied with the outcomes of TKA [7].

Regarding knee flexion, as dictated by the payment system of the Taiwan National Health Insurance system, TKA patients must exhibit knee flexion angle $\geq 90^{\circ}$ before they can be discharged. The participants interviewed in this study indicated that they were still unable to squat; although they had sitting toilets, normal height chairs and beds, improved postoperative joint range of motion, and did not need to sit on the floor, they still encountered multiple inconveniences in daily life. Hemmerich et al. indicated that a mean maximum flexion of $157^{\circ} \pm 6^{\circ}$ at the knee joint was required for squatting with heels up [22]. Mulholland and Wyss emphasized that artificial joints and product functions must match culture and patient lifestyle habits. Although East Asians may need to squat in everyday life or sit cross-legged during religious worship activities, these motions requiring great ranges of motion remain difficult for the patients [14].

\subsection{Changes in ADL Difficulty before and after Surgery}

Prior to surgery, the participants were largely able to independently care for themselves without assistance from others; many are even able to assist through, for example, bathing grandchildren or preparing meals. Difficulties were encountered in the inability to walk long distances (because of pain), thus affecting personal shopping activities, exercise habits, travel, and using public transportation. The participants in more desirable circumstances had beds, tables, chairs, and toilets of appropriate height, enabling them to perform regular functions in daily life unimpeded regardless of knee function. Subjective experiences drawn from the interviews confirmed the results of past studies, including those of Chen et al., who examined 92 TKA patients [23]. The research results indicated that patient physical function (eating, bathing, toileting, dressing, grooming, walking, going up and down stairs, moving in and out of bed, and moving in and out of 
chair) prior to surgery was largely favourable (17 out of 18), indicating that most of the patients were able to care for themselves before surgery. The lowest score was for climbing stairs and chair sitting, indicating that these activities are more difficult.

The participants in this study reported experiencing some difficulty in performing daily life activities during the initial postoperative period. These results are consistent with those of Lin et al. [24], who examined the physical postoperative recovery of 83 TKA patients. Lin et al. found that the patients averaged a physical function score of 14.95 (out of 18) 2 weeks after hospital discharge, with stair climbing exhibiting the lowest score of 1.02 ( 0 - 2 points). Four weeks after discharge, patient scores improved to an average of 16.59 points, with stair climbing exhibiting a score of 1.43 pointsboth lower than the preoperative scores. The participants in the current study attained normal function in daily routines and outdoor activities 1 - 3 years post operation, indicating a significant improvement compared with the preoperative scores. These personal experiences drawn from knee arthritis patients spanning from the preoperative to postoperative periods are extremely valuable and can be used as references in preoperative health education for patients, providing them with empirical data drawn from real patient experiences.

\section{Conclusion}

The current results revealed that different participants experienced knee joint pain, difficulty in walking, an inability to walk long distances, and limited joint range of motion preoperatively, and that though the participants had no difficulty caring for themselves, the limitations on mobility and freedom of movement significantly affected their mood. Pain eased after surgery, but participant's ability to walk and participate in outdoor activities varied widely within 2 - 3 months of hospital discharge. However, all the participants exhibited positive results in $1-3$ years post operation, improved moods, and approached normality in daily life. Although joint range of motion improved significantly, participants were still unable to squat.

\section{Study Limitation and Recommendation}

This study conducted purposive sampling at one medical centre and one teaching hospital. As such, the study was unable to be expanded to include more medical institutions. Therefore, future studies should examine patients from hospitals of different levels and with varying characteristics to extend the scope and generalizability of this research. Furthermore, the patient experiences obtained in this study come from different participants and may have been affected by the personal background characteristics of each participant. As such, this study recommends that future research be conducted in a longitudinal fashion on the same group of patients.

The results of this study and real patient experiences can be used in future medical communications, especially in the design of health education for knee joint replacement patients. Preoperative measures should focus on the topics that patients are most concerned with, such as pain improvement and walking ability, to provide information 
and professional advice with an empirical basis. For instance, patients can be reassured that pain will be eased and joint range of motion will improve, though squatting will continue to be difficult. Furthermore, patients should be informed that ideal walking and mobility recovery cannot occur until after a period of time post operation. These measures will assist patients in developing realistic expectations and satisfaction towards TKA surgery, and the provision of preoperative information will enhance postoperative results and improve patient confidence.

\section{Acknowledgements}

This project was financially sponsored by the Ministry of Science and Technology (Grant No: MOST 103-2314-B-038-046-MY3). The authors thank Professor Kiyoko Makimoto for her support and all the participants who participated in this research for their cooperation.

\section{References}

[1] Walker, J. (2012) Care of Patients Undergoing Joint Replacement. Nursing Older People, 24, 14-20. http://dx.doi.org/10.7748/nop2012.02.24.1.14.c8898

[2] Ethgen, O., Bruyère, O., Richy, F., Dardennes, C. and Reginster, J.Y. (2004) Health-Related Quality of Life in Total Hip and Total Knee Arthroplasty. The Journal of Bone and Joint Surgery, 86, 963-974.

[3] Jones, A. and Pohar, S. (2012) Health-Related Quality of Life after Total Joint Arthroplasty: A Scoping Review. Clinical Geriatric Medicine, 28, 395-429. http://dx.doi.org/10.1016/j.cger.2012.06.001

[4] Chen, H.S. (2008) Relationship between Length of Stay and Quality of Life and Functional Status after Total Joint Replacement Patients. Unpublished MS Thesis, China Medical University, Taichung.

[5] Chung, F.Y. (2009) Exploring Health-Related Quality of Life in Patients Undergoing Revision Total Hip Replacement or Revision Total Knee Replacement. Unpublished MS Thesis, Kaohsiung Medical University, Taiwan.

[6] Hsu, H.Y. (2010) Health-Related Quality of Life before and after Total Knee Replacement. Unpublished MS Thesis, National Defense Medical Center, Taipei.

[7] Nunez, M., Lozano, L., Nunez, E., Segur, J.M., Sastre, S., Macule, F., Ortega, G. and Suso, S. (2009) Total Knee Replacement and Health-Related Quality: Factors Influencing LongTerm Outcomes. Arthritis \& Rheumatism, 61, 1062-1069. http://dx.doi.org/10.1002/art.24644

[8] Nilsdotter, A.K., Toksvig-Larsen, S. and Roos, E.M. (2009) Knee Arthroplasty: Are Patients' Expectations Fulfilled? Acta Orthopaedica, 80, 55-61. http://dx.doi.org/10.1080/17453670902805007

[9] Chen, Y.C. (2009) Study on Life Quality of Total Knee Replacement Surgery Patients. Unpublished MS Thesis, National Defense Medical Center, Taipei.

[10] Lin, P.C., Chang, S.Y. and Chuang, C.Y. (2000) Quality of Life and Its Related Factors for Patients after Total Joint Replacement. The Journal of Nursing Research, 8, 165-176.

[11] Chang, H.Y. (2011) A Longitudinal Long-Term Study of Revision Total Hip Replacement or Revision Total Knee Replacement. Unpublished MS Thesis, Kaohsiung Medical University, Taiwan. 
[12] Fujita, K., Makimoto, K. and Hotokebuchi, T. (2006) Qualitative Study of Osteoarthritis Patients' Experience before and after Total Hip Arthroplasty in Japan. Nursing and Health Sciences, 8, 81-87. http://dx.doi.org/10.1111/j.1442-2018.2006.00253.x

[13] Gustafsson, B.A., Ekman, S.L., Ponzer, S. and Heikkila, K. (2010) The Hip and Knee Replacement Operation: An Extensive Life Event. Scandinavian Journal of Caring Sciences, 24, 663-670. http://dx.doi.org/10.1111/j.1471-6712.2009.00759.x

[14] Mulholland, S.J. and Wyss, U.P. (2001) Activities of Daily Living in Non-Western Cultures: Range of Motion Requirements for Hip and Knee Joint Implants. International Journal of Rehabilitation Research, 24, 191-198. http://dx.doi.org/10.1097/00004356-200109000-00004

[15] Polit, D.F. and Beck, C.T. (2012) Nursing Research: Generating and Assessing Evidence for Nursing Practice. 9th Edition, Lippincott Williams \& Wilkins, Philadelphia.

[16] Lincoln, Y.S. and Guba, E.G. (1985) Naturalistic Inquiry. SAGE, Thousand Oaks, 289-331. http://dx.doi.org/10.1016/0147-1767(85)90062-8

[17] Wilkie, P. (1997) Ethical Issues in Qualitative Research in Palliative Care. Palliative Medicine, 11, 321-324. http://dx.doi.org/10.1177/026921639701100411

[18] Lin, P.C. (2011) An Evaluation of the Effectiveness of Relaxation Therapy for Patients Receiving Joint Replacement Surgery. Journal of Clinical Nursing, 21, 601-608. http://dx.doi.org/10.1111/j.1365-2702.2010.03406.x

[19] Desmeules, F., Dionne, C.E., Belzile, E., Bourbonnais, R. and Frémont, P. (2009) Waiting for Total Knee Replacement Surgery: Factors Associated with Pain, Stiffness, Function and Quality of Life. BMC Musculoskeletal Disorders, 10, 52.

[20] Parker, R.J. (2011) Evidence-Based Practice Caring for a Patient Undergoing Total Knee Arthroplasty. Orthopaedic Nursing, 30, 4-8. http://dx.doi.org/10.1097/NOR.0b013e3182057451

[21] Rudan, J.F., Harrison, M.M. and Grant, H.J. (2009) Determining Patient Concerns before Joint Arthroplasty. Journal of Arthroplasty, 24, 1115-1119. http://dx.doi.org/10.1016/j.arth.2008.08.007

[22] Hemmerich, A., Brown, H., Smith, S., Marthandam, S.S. and Wyss, U.P. (2006) Hip, Knee, and Ankle Kinematics of High Range of Motion Activities of Daily Living. Journal of Orthopedic Research, 24, 770-781. http://dx.doi.org/10.1002/jor.20114

[23] Chen, S.R., Chen, C.S. and Lin, P.C. (2014) The Effect of Educational Intervention on the Pain and Rehabilitation Performance of Patients Who Undergo a Total Knee Replacement. Journal of Clinical Nursing, 23, 279-287. http://dx.doi.org/10.1111/jocn.12466

[24] Lin, P.C., Hung, S.H., Wu, H.F., Hsu, H.C., Chu, C.Y. and Su, S.J. (2011) The Effects of a Care Map for Total Knee Replacement Patients. Journal of Clinical Nursing, 20, 3119-3127. http://dx.doi.org/10.1111/j.1365-2702.2011.03804.x 
Submit or recommend next manuscript to SCIRP and we will provide best service for you:

Accepting pre-submission inquiries through Email, Facebook, LinkedIn, Twitter, etc. A wide selection of journals (inclusive of 9 subjects, more than 200 journals)

Providing 24-hour high-quality service

User-friendly online submission system

Fair and swift peer-review system

Efficient typesetting and proofreading procedure

Display of the result of downloads and visits, as well as the number of cited articles

Maximum dissemination of your research work

Submit your manuscript at: http://papersubmission.scirp.org/ 